1170 WHO CAN AND WHO WANTS TO WORK UNTIL RETIREMENT AGE? THE IMPACT OF WORK FACTORS ON THE SUBJECTIVE EMPLOYMENT PERSPECTIVE

HM Hasselhorn*, M Ebener. Department of Occupational Health Science, University of Wuppertal, Germany

\subsection{6/oemed-2018-ICOHabstracts. 121}

Introduction Anticipating demographic changes, many European states have increased official pension entitlement age, some countries by ten years. Prospectively, working lives of the work force will be extended; but still today, most people leave employment long before reaching official retirement age. Who CAN and who WANTS to work until regular retirement age? Are 'CAN' and 'WANT' connected to work and private factors in a similar way?

Methods Data base is the second wave (2014) of the lidA cohort study (www.lida-study.de) which is investigating work, health and employment among older workers born in 1959 or 1965 $(n=4.042)$ in a representative sample of the socially employed population in Germany by means of a personal interview (CAPI). The statistically predictive power of work and private factors for self-reported ability (I CAN work until 65+years) and motivation to work (I WANT to work until 65 +years) was calculated by means of multivariate logistic regression analyses.

Results Older workers, men, higher educated, having high work ability and high influence at work were significantly related to longer work perspectives for both outcomes CAN and WANT. Quantitative demands and partner's health were neither associated with CAN nor WANT. Good self-rated health was predicting CAN but not WANT. Good leadership quality, high possibilities for development at work, high (!) household obligations and a negative attitude towards early retirement in the private surrounding predicted motivation to work longer (WANT) but not CAN.

Discussion Findings indicate the relevance of work and private factors for the subjective employment perspective. Yet diverging findings for self-rated ability to work longer and motivation to work longer confirm the differences between these two concepts. A conclusion is that both outcomes may be of relevance for sustained employability but require different interventions on the work level.

\section{DOES PHYSICAL WORKLOAD MODERATE THE INFLUENCE OF OBESITY ON WORK ABILITY AMONG CONSTRUCTION WORKERS?}

\footnotetext{
${ }^{1}$ Karin Proper*, ${ }^{2}$ Susanne Tonnon, ${ }^{3}$ Suzan Robroek, ${ }^{2}$ Allard Van der Beek, ${ }^{3}$ Alex Burdorf, ${ }^{2}$ Hiddie van der Ploeg, ${ }^{4}$ Margo Caspers. ${ }^{1}$ National Institute for Public Health and The Environment, Bilthoven, The Netherlands; ${ }^{2}$ Department of Public and Occupational Health, VU University Medical Centre, Amsterdam, The Netherlands; ${ }^{3}$ Erasmus Medical Centre, Department of Public Health, Rotterdam, The Netherlands; ${ }^{4}$ Volandis, Harderwijk, The Netherlands
}

\subsection{6/oemed-2018-ICOHabstracts.122}

Introduction There is few research on the causal pathways in the link between obesity and work ability. Furthermore, there are indications that the effects of obesity on work ability differ for workers with different levels of physical workload. This study aimed to investigate the moderating effect of physical workload in the relation between obesity and work ability. Methods A longitudinal study was conducted among 36,435 Dutch construction workers who participated in at least two periodic medical examinations during the years 2008-2015. Logistic regression analyses were used to investigate the effect of manual material handling and strenuous work postures on the association between obesity and work ability. Confounding effects were tested for age, educational level, smoking, vigorous physical activity, psychosocial work demands, and working hours. Additive interaction between obesity and physical workload on work ability was tested using the relative excess risk due to interaction (RERI).

Results Construction workers with overweight (OR=1.09; 95\% CI: 1.02 to 1.16$)$ or obesity $(\mathrm{OR}=1.27$; 95\% CI: 1.17 to 1.38) had an increased risk of poor/moderate work ability. Exposure to manual material handling $(\mathrm{OR}=1.58 ; 95 \% \mathrm{CI}: 1.49$ to $1.68)$ or strenuous work postures $(\mathrm{OR}=1.80 ; 95 \% \mathrm{CI}$ : 1.70 to 1.90) also increased the risk of poor/moderate work ability. The effect of the combination of obesity with high physical workload was greater than the sum of the individual effects (strenuous work postures: $\mathrm{RERI}=0.39$; $95 \% \mathrm{CI}: 0.10$ to 0.67 ; manual material handling: $\mathrm{RERI}=0.26$; $95 \% \mathrm{CI}: 0.02$ to 0.51 ).

Discussion Obesity and high physical workload were associated with poor work ability and had a synergistic, negative effect on work ability. To prevent poor work ability, there is a need for interventions that promote a healthy lifestyle and increase physical capacity, as well as for interventions that tailor physical workload to the individual physical capacity.

\section{SOCIETAL PARTICIPATION OF OLDER PEOPLE WITH AND WITHOUT A CHRONIC DISEASE: PARTICIPATION IN PAID WORK, VOLUNTEERING AND PROVIDING INFORMAL CARE}

${ }^{1}$ Micky Scharn, ${ }^{1}$ Allard J van der Beek, ${ }^{2}$ Bianca Suanet, ${ }^{2,3}$ Martijn Huisman, ${ }^{1}$ Cécile RL Boot. 'Department of Public and Occupational Health, Amsterdam Public Health research institute, VU University Medical Centre Amsterdam, The Netherlands; ${ }^{2}$ Department of Epidemiology and Biostatistics, Amsterdam Public Health research institute, VU University Medical Centre Amsterdam, The Netherlands; ${ }^{3}$ Department of Sociology, VU University Amsterdam, The Netherlands

\subsection{6/oemed-2018-ICOHabstracts. 123}

Background Societal participation in the Netherlands has increased due to policy changes. We do not know whether this increase in societal participation also counts for people with chronic disease. This study aims to explore differences and similarities in 3 forms of societal participation, having paid work, providing informal care and involvement in volunteer work, between people with and without a chronic disease in 2002 and 2012.

Methods Respondents $(n=1,779)$ aged between 55 and 64 years who participated in the representative Longitudinal Ageing Study Amsterdam in 2002 or 2012 were included. We tested differences in (combinations of) having paid work, providing informal care or volunteer work between participants with and without a chronic disease by regression analyses, taking into account sociodemographic confounders and effect modification by year (2002 vs 2012).

Results Having a chronic disease was associated with not having paid work (OR: $0.7 ; 95 \% \mathrm{CI}: 0.6$ to 0.9 ), but not with providing informal care (OR: 0.9 ; $95 \% \mathrm{CI}: 0.7$ to 1.2 ) or volunteer work (OR: 0.9; 95\% CI: 0.7 to 1.1). No differences were found between workers with and without chronic disease for combinations of societal participation. We found effect modification by year; in 2012, people without (OR: 2.7; 95\% CI: 1.7 to 4.5 ) and with chronic disease (OR: 3.0; 